ScIDice

\section{Oral Health Related Quality of Life (OHRQOL) among Residents in a Care Home in Terengganu, Malaysia; A Cross Sectional Study}

\author{
International Journal of Dentistry and Oral Science (IJDOS) \\ ISSN: $2377-8075$
}

Research Article

Farah Natashah Mohd ${ }^{1}$, Abdul Hadi Said ${ }^{2}$, Susi Sukmasari ${ }^{3}$, Nor Iziana Ismail ${ }^{4}$, Nor Mulyani Musa ${ }^{4}$

${ }^{1}$ Lecturer, Special Needs Dentistry Unit, Kulliyyah of Dentistry, International Islamic University Malaysia, Kuantan, Malaysia.

${ }^{2}$ Lecturer, Family Medicine Department, Kulliyyah of Medicine, International Islamic University Malaysia, Kuantan, Malaysia.

${ }^{3}$ Lecturer, Paediatric Dentistry Unit, Kuliyyah of Dentistry, International Islamic University Malaysia, Kuantan, Malaysia.

${ }^{4}$ Undergraduate student, Kulliyyah of Dentistry, International Islamic University Malaysia, Kuantan, Malaysia.

\title{
Abstract
}

Objective: This study aimed to assess the oral health related quality of life (OHRQOL) among residents living in a care home in Terengganu, Malaysia and its associated factors.

Method: A cross sectional study using universal sampling to assess the OHRQOL among residents in a care home in Terengganu state was done from July to August 2018. The OHRQOL was assessed using a validatedshort Oral Health Impact Profile (S-OHIP) Malay version questionnaire. Association between OHRQOL and sociodemographic profile as well as their oral health status was also analysed.

Results: The mean total S-OHIP score was $6.28 \pm 5.72$. The most commonly reported S-OHIP dimension was psychological discomfort due to food getting stuck with a mean score of $1.33 \pm 1.64$. On the other hand, avoided going out was the least impact with a mean score of $0.27 \pm 0.94$. Those who were able to ambulate had better OHRQOL while those who perceived they need dental treatments have poorer OHRQOL. Surprisingly, those with underlying stroke have lower S-OHIP score indicates better OHRQOL compared to those without stroke. Furthermore, there was no significant association found between OHRQOL and their oral health status.

Conclusion: The S-OHIP score of the participants was low compared to the other local studies among other population indicating that they have good OHRQOL. Inability to ambulate and self-perceived need for dental treatments were shown to give more impact towards their OHRQOL. Despite the finding that the impact was low among the residents, it is important to make sure they receive continuous oral care to maximise their OHRQOL as well as their overall quality of life.

Keywords: Oral Health Related Quality Of Life; Residents; Care Home.

\section{Introduction}

Malaysia is facing a prospect of an aging population by 2030 with a yearly increment about $2.2 \%$ of the elderly population [1-3]. Together with this increment, the number of care homes in Malaysia also increased. In most studies, it was found that those who lived in care homes were merely elderly aged 60 years and above. More importantly, previous studies had found that people living in care homes had poor oral health [4-7]. Some authors found that the risk factors for the poor oral health were increasing age [7] and limited access to dental care [4, 6]. Another factor was the inability to perform daily oral self-care due to physical disability or non-ambulatory $[6,8]$.
Oral health is very important and reduced in oral functions such as due to toothache or reduced number of functional teeth may affect the oral health related quality of life (OHRQOL) of any living person, not to mention people in residential homes or care homes [6]. Furthermore, Monaghan N et al., (2016) found that people receiving care also had a higher unmet dental need [7], fewer teeth, and more poorly fitting dentures [9].

Although there were a few local studies done among residents in care homes, none of them specifically assessed the OHRQOL of the residents. A few studies were done to assess the oral health among residents in care homes which focused on the dental status using DMF-T (decay, missing, filling-total) index of the residents

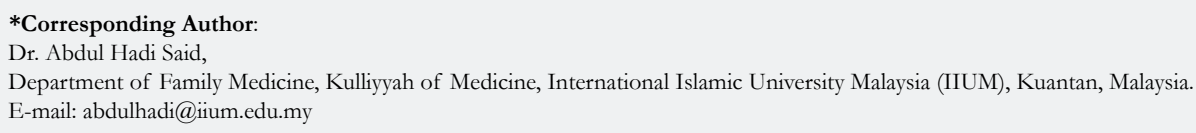

Citation: Farah Natashah Mohd, Abdul Hadi Said, Susi Sukmasari, Nor Iziana Ismail, Nor Mulyani Musa. Oral Health Related Quality of Life (Ohrqol) among Residents in a Care Home in Terengganu, Malaysia; A Cross Sectional Study. Int J Dentistry Oral Sci. 2020;7(11):976-980. doi: http://dx.doi.org/10.19070/2377-8075-20000194

Copyright: Abdul Hadi Said ${ }^{\circ}$ 2020. This is an open-access article distributed under the terms of the Creative Commons Attribution License, which permits unrestricted use, distribution and reproduction in any medium, provided the original author and source are credited. 
$[6,7]$. Meanwhile, other local studies by Sinor 2013 and Enny E 2015 were focused mainly on the general elderly group $[6,10]$. Several local studies were done to assess OHRQOL among adults in Kuantan [11], Selangor [12] and Klang Valley area [13] but none involve residents in care homes. Therefore this study is needed to assess the OHRQOL of residents in a local care home which could serve as a piece of baseline information for our country. The aimed of our study was to determine the level of OHRQOL among the residents in a care home and its associated factors.

\section{Method}

\section{Study design and population}

This was a cross sectional study done among residents in a care home in Terengganu state, Malaysia. Most of the care homes in Malaysia are registered under the Ministry of Welfare.

In Malaysia, the two largest care homes registered under the Ministry of Welfare is situated in east coast Malaysia (Terengganu state) and west Malaysia (Selangor state). This care home in the east coast Malaysia is known as 'Rumah Ehsan Dungun'. This care home caters for those who have physical impairments, low socioeconomic status, absence of family members and those with chronic medical illnesses. The residents for this care home comprised of the population from across the country. There were a total of 120 beds available in 'Rumah Ehsan Dungun', however, only 85 beds were occupied during the period of this study conducted. This study used universal sampling in which all registered residents during the period of the study were invited to participate. The inclusion criteria was all registered residents of 'Rumah Ehsan Dungun' while the exclusion criteria were those who were hospitalized during the period of this study, those who were unable to give consent and residents with cognitive impairment. After the exclusion, there were 75 residents eligible for the study. The data collection was done from July to August 2018.

\section{Data Collection and Research Instrument}

The validated short version of the Oral Health Impact Profile (S-OHIP) questionnaire was used in this study to assess the OHRQOL of the residents. It was validated in Malay and showed good consistency and validity [14]. The questionnaire consists of 14 questions concerning 7 domains which are functional limitation, physical pain, psychological discomfort, physical disability, psychological discomfort, social disability and handicap [14]. Responses of each item are made on a Likert scale and coded as; $0=$ never, $1=$ hardly ever, $2=$ occasionally, $3=$ fairly often, and $4=$ very often [14]. The total scores range from 0 to 56 where 0 indicates no impact and 56 indicates the worst impact on a person's OHRQOL. The higher score indicates poorer OHRQOL. The researchers approached each resident at their bedside and gave a brief explanation regarding the objectives and the procedure of the study. After obtaining the consent, the subjects were interviewed individually which lasted about ten minutes. The sociodemographic data includes gender, age, race, ability to ambulate and medical illness was also obtained to assess for association. Intraoral examination was done by a qualified dental specialist to assess for dentate status and DMF-T score in order to assess for its association with OHRQOL of the participants.

\section{Data Analysis}

All statistical analysis was done using IBM SPSS Statistics for Windows, Version 24.0. Armonk, NY: IBM Corp. Test of normality was performed for continuous data (OHIP score). The normally distributed data were reported using mean and standard deviation. Association between normally distributed data (S-OHIP score) and categorical data was analysed using independent t-test. Correlation between S-OHIP score with age and DMFT score was analysed using Pearson correlation. Association was considered significant if the $\mathrm{p}$-value is $<0.05$. Multiple linear regression was employed to determine the relationship between OHRQOL and the associated factors with a p-value less than 0.05 .

\section{Results}

Table 1 shows the S-OHIP score of the participants. The higher the S-OHIP score indicates a higher impact on the quality of life (poorer OHRQOL). The mean total score was 6.28 with SD \pm 5.72. The most commonly reported S-OHIP dimension was psychological discomfort due to food getting stuck with a mean score of 1.33. On the other hand, avoided going out was the least impact with a mean score of 0.27 .

Table 2 shows that ability to ambulate, underlying stroke, selfperceived dental treatment needs and oral health satisfaction were significantly associated with OHRQOL. Those who were able to ambulate and satisfied with their oral health had lower SOHIP score indicates better OHRQOL. Meanwhile, those who perceived they need dental treatment had higher score indicates poorer OHRQOL. Interestingly, residents with underlying stroke also had a lower score indicates better OHRQOL compare to those without underlying stroke.

Multivariate analysis using multiple linear regression was performed to adjust for confounding factors associated with OHIP 14 score. Similar to the previous bivariate analysis, it was found that those who were able to ambulate(Coef. $=-0.229,95 \% \mathrm{CI}$ : $-4.978,-0.226, \mathrm{p}=0.032$ ), andhave underlying stroke (Coef.= $-0.247,95 \%$ CI: $-6.287,-0.556, \mathrm{p}=0.020)$ were associated with lower OHIP score which indicates better OHRQOL. Meanwhile, those who perceived they need dental treatment (Coef. $=-0.238$, 95\% CI: 0.059, 5.365,p=0.045)have higher OHIP score indicates poorer OHRQOL. In addition, there was no significant relationship found between perceived oral health satisfaction and OHIP score suggesting that it was just a confounding factor.

\section{Discussion}

\section{Oral Health Related Quality Of Life (OHRQOL) of the participants}

It is fascinating to know that the total mean OHIP score of participants in our study waslow compared to local studies done among adults in Selangor [14], Klang valley [12] and Kuantan [11] (Table 1). Another study was done among adults living with HIV/AIDS in Malaysia also reported slightly higher S-OHIP(M) score compared to our study [15]. This lower score means that they have better OHRQOL compared to participants from the previous studies. This difference could be due to differences in population studied. This finding also contradicted with what most authors 
Table 1. S-OHIP -14 (M) score of the participants.

\begin{tabular}{|c|c|c|c|c|}
\hline \multirow[b]{2}{*}{ S-OHIP(M) domain and item } & \multicolumn{3}{|c|}{ Prevalence (\%) } & \multirow[b]{2}{*}{ Mean \pm SD } \\
\hline & Occasional & Often & $\begin{array}{l}\text { Very } \\
\text { often }\end{array}$ & \\
\hline \multicolumn{5}{|l|}{ Functional limitation } \\
\hline Difficulty chewing any foods & $3(4.0)$ & $7(9.3)$ & $10(13.3)$ & $0.95 \pm 1.52$ \\
\hline Problems caused bad breath & $2(2.7)$ & $15(20.0)$ & $9(12.0)$ & $1.13 \pm 1.61$ \\
\hline \multicolumn{5}{|l|}{ Physical pain } \\
\hline Discomfort eating any food & $4(5.3)$ & $15(20.0)$ & $9(12.0)$ & $1.25 \pm 1.57$ \\
\hline Ulcers in mouth & $2(2.7)$ & $4(5.3)$ & $6(8.0)$ & $0.57 \pm 1.27$ \\
\hline \multicolumn{5}{|l|}{ Psychological discomfort } \\
\hline Discomfort due to food getting stuck & $2(2.7)$ & $18(24.0)$ & $10(13.3)$ & $1.33 \pm 1.64$ \\
\hline Felt shy & $3(4.0)$ & $7(9.3)$ & $10(13.3)$ & $0.89 \pm 1.54$ \\
\hline \multicolumn{5}{|l|}{ Physical disability } \\
\hline Avoided eating certain foods & $5(6.7)$ & $9(12.0)$ & $12(16.0)$ & $1.20 \pm 1.60$ \\
\hline Avoided smiling & $1(1.3)$ & $3(4.0)$ & $6(8.0)$ & $0.47 \pm 1.22$ \\
\hline \multicolumn{5}{|l|}{ Psychological disability } \\
\hline Sleep been disturbed & $3(4.0)$ & $6(8.0)$ & $7(9.3)$ & $0.69 \pm 1.39$ \\
\hline Concentration been disturbed & $3(4.0)$ & $1(1.3)$ & $5(6.7)$ & $0.40 \pm 1.10$ \\
\hline \multicolumn{5}{|l|}{ Social disability } \\
\hline Avoided going out & & & & $0.27+0.94$ \\
\hline $\begin{array}{c}\text { Problems in carrying out daily activi- } \\
\text { ties }\end{array}$ & $0(0)$ & $3(4.0)$ & $6(8.0)$ & $0.44 \pm 1.21$ \\
\hline \multicolumn{5}{|l|}{ Handicap } \\
\hline Had to spend a lot of money & $0(0)$ & $1(1.3)$ & $8(10.7)$ & $0.47 \pm 1.28$ \\
\hline Felt less confident & $1(1.3)$ & $3(4.0)$ & $5(6.7)$ & $0.41 \pm 1.15$ \\
\hline Total OHIP-14 & & & \multicolumn{2}{|c|}{ Mean: $6.28 \pm 5.72$} \\
\hline
\end{tabular}

Table 2. Factors associated with oral health related quality of life (OHIP-14).

\begin{tabular}{|c|c|c|c|}
\hline & \multicolumn{3}{|c|}{ OHIP-14 SCORE } \\
\hline VARIABLES & $\mathrm{n}$ & Mean \pm SD & $\mathbf{P}$-value \\
\hline \multicolumn{4}{|l|}{ Gender } \\
\hline Female & 34 & $7.12 \pm 6.38$ & 0.25 \\
\hline Male & 41 & $5.59 \pm 5.09$ & \\
\hline Mean age (in years) \pm SD & $65.6 \pm 11.6$ & $6.28 \pm 5.72$ & 0.41 \\
\hline \multicolumn{4}{|l|}{ Race } \\
\hline Malay & 65 & $6.58 \pm 5.50$ & 0.24 \\
\hline Others & 10 & $4.30 \pm 7.01$ & \\
\hline \multicolumn{4}{|l|}{ Able to ambulate } \\
\hline Yes & 39 & $4.90 \pm 5.02$ & 0.028 \\
\hline No & 36 & $7.78 \pm 6.12$ & \\
\hline \multicolumn{4}{|l|}{ Brushing teeth } \\
\hline Independent & 50 & $5.80 \pm 5.61$ & 0.31 \\
\hline Dependent & 25 & $7.24 \pm 5.94$ & \\
\hline \multicolumn{4}{|l|}{ Smoking status } \\
\hline Active smoker & 4 & $5.00 \pm 3.56$ & 0.74 \\
\hline Non/ex-smoker & 41 & $6.00 \pm 5.72$ & \\
\hline \multicolumn{4}{|l|}{ Diabetes mellitus } \\
\hline Yes & 20 & $7.90 \pm 7.23$ & 0.14 \\
\hline No & 55 & $5.69 \pm 5.02$ & \\
\hline \multicolumn{4}{|l|}{ Stroke } \\
\hline Yes & 16 & $3.69 \pm 3.24$ & 0.04 \\
\hline No & 59 & $6.98 \pm 6.06$ & \\
\hline \multicolumn{4}{|l|}{ Perceived dental treatment needs } \\
\hline Yes & 36 & $8.50 \pm 6.11$ & 0.001 \\
\hline No & 39 & $4.23 \pm 4.52$ & \\
\hline \multicolumn{4}{|l|}{ Perceived oral health satisfaction } \\
\hline Satisfied & 51 & $4.88 \pm 5.22$ & 0.002 \\
\hline Not satisfied & 24 & $9.25 \pm 5.71$ & \\
\hline \multicolumn{4}{|l|}{ Oral health status } \\
\hline Decay (mean $\pm \mathrm{SD})$ & $4.89 \pm 5.46$ & $6.28 \pm 5.72$ & 0.79 \\
\hline Missing (mean $\pm \mathrm{SD})$ & $20.08 \pm 10.75$ & $6.28 \pm 5.72$ & 0.92 \\
\hline Filling (mean $\pm \mathrm{SD})$ & $0.17 \pm 0.60$ & $6.28 \pm 5.72$ & 0.6 \\
\hline Total DMFT (mean \pm SD) & $25.15 \pm 7.88$ & $6.28 \pm 5.72$ & 0.99 \\
\hline \multicolumn{4}{|l|}{ Edentulous state } \\
\hline Complete edentulous & 20 & $5.85 \pm 5.87$ & 0.7 \\
\hline Full or partially dentate & 55 & $6.44 \pm 5.72$ & \\
\hline
\end{tabular}


Table 3. Multiple linear regression analysis to determine factors associated with oral health related quality of life (OHIP-14 score).

\begin{tabular}{|c|c|c|c|c|}
\hline Variables & B & Standardised Coef & 95\% CI & P-value \\
\hline $\begin{array}{c}\text { Ability to ambulate } \\
\text { (No as RC) } \\
\text { Yes }\end{array}$ & \multicolumn{3}{|l|}{} \\
\cline { 2 - 5 } & -2.602 & -0.229 & $-4.978,-0.226$ & 0.032 \\
\hline $\begin{array}{c}\text { Stroke (No as RC) } \\
\text { Yes }\end{array}$ & -3.421 & -0.247 & $-6.287,-0.556$ & 0.02 \\
\hline $\begin{array}{c}\text { Perceived dental treatment needs(No as RC) } \\
\text { Yes }\end{array}$ & 2.712 & 0.238 & $0.059,5.365$ & 0.045 \\
\hline $\begin{array}{c}\text { Perceived oral health satisfaction (No as RC) } \\
\text { Yes }\end{array}$ & -2.328 & -0.191 & $-5.167,0.520$ & 0.108 \\
\hline
\end{tabular}

$\mathrm{RC}=$ Reference category

found $[16,17]$ where residents in care homes have a higher impact on their OHQOL when compared with the same age group in Adult Dental Health Survey (ADHS) participants [18]. It is also found in another study that dry mouth and dental pain(physical pain) [9] associated with higher S-OHIP score which is in disagreement with our findings where psychological discomfort contributed to the highest S-OHIP score which consistent with a local study done in Kuantan [11]. A possible hypothesis for this was that the participants in our study most probably satisfied with the oral care provided by the staff and the nearby dental team.

\section{Factors associated with OHRQOL}

It was found that those who were non-ambulatory has higher S-OHIP(M) score which indicates a significant impact to their OHRQOL (Table 2 and Table 3). This shows the importance of capability for self-care in order to attain a better quality of life [19]. Although the residents have access to the dental clinic nearby, they have to be sent to the clinic instead of the dentist coming over for dental treatments on the bedside. The possible causes for this could be a shortage of manpower working in the dental clinic and insufficient knowledge on dental management of bedridden with chronic disease patients. Therefore, it is crucial to train the undergraduate dental students with exposure to community settings in the management for people with disabilities including bedridden elderly and institutionalized adults with special needs (eg: Cerebral palsy, Down Syndrome, mental health issues). Thus, in the future, they will become confident in managing these people in community-based dental settings.

It was also observed that those who perceived they need dental treatments have more impact on their oral health in which coincides with previous studies $[14,20]$ (Table 2 and Table 3). This finding showed that OHRQOL was poorer for those who perceived they need dental care as they were unsatisfied with their oral condition.

However, on the other hand, it is intriguing to find that in this study, those who have stroke have better OHRQOL in comparison with their counterparts (Table 2 and Table 3 ). The possible explanation for this could be that those who have more comorbidities complaint less about their oral problems unless it becomes severe and symptomatic [21]. Previous studies had found that elderly in care homes would not demand anything more than what was provided at the care homes [21]. In contrast, studies have found that patients with underlying stroke had lower OHIP score than the opposite group $[22,23]$. The reasons behind this were people with underlying stroke would have difficulties in physical activities including tooth-brushing and self-care.

It is compelling to learn that DMF-T and edentulous state did not affect the OHRQOL of the residents in this care home (Table 2) with $p>0.05$ which contradicted with the findings from systematic review [24]. The difference could be the search key term for "care home" and "residents" were not included in the review. As previous research also found that the elderly group has lower OHRQOL score compared to the younger groups [13]. People living in care homes perhaps have less to expect and do not complain as much as those living in the community [21].

\section{Strengths and limitations}

The limitation of this study was it involved only one care home. Therefore, the findings may not be generalised to other care homes in Malaysia. Apart from this, questions related to oral problems were not included to see if there was any association with the OHRQOL. However, this was the first study done in Malaysia that focused on OHRQOL among residents in a care home and the finding should provide us with a baseline knowledge regarding their OHRQOL.

\section{Conclusion}

In conclusion, the OHIP score among the participants was low indicating that they have good OHRQOL. Inability to ambulate and self-perceived need for dental treatments were shown to give more impact towards their OHRQOL. Despite the finding that the impact was low among the residents, it is important to make sure they receive continuous oral care to maximise their OHRQOL as well as their overall quality of life.

\section{Acknowledgement}

We would like to thank all the residents and staff of Rumah Ehsan Dungun for their hospitality during the data collection. We also would like to thank the Department of Welfare Malaysia for the permission to conduct this study. 


\section{Ethics}

This study was approved by the International Islamic University of Malaysia (IIUM) Research Ethics Committee (IREC) for the ethical consideration with IREC 2018-048 dated 31st January 2018.

\section{Source of Funding}

This study was part of the project funded by IIUM Flagship Research Initiative Grant Scheme (IRF) 2019 PROJECT (IRF19022-0022).

\section{Author's Contribution}

Farah Natashah Mohd initiated the study, finalisisng the title and study instrument, Abdul Hadi Said provided the study designed and statistical analysis, Susi Sukmasari did the literature review and discussion part, Nor Iziana Ismail and Nor Mulyani Musa did the data collection and data entry into spss. All authors reviewed the finalised manuscript before submission.

\section{References}

[1]. Tey NP, Siraj SB, Kamaruzzaman SB, Chin AV, Tan MP, Sinnappan GS, et al. Aging in Multi-ethnic Malaysia. Gerontologist. 2016 Aug;56(4):603-9. Pubmed PMID: 26553738.

[2]. Malaysia to be aged nation by 2030, in The Star. 2016.

[3]. Perempuan KP, Anak P, Statistik BP. Pembangunan Manusia Berbasis Gender 2016. Jakarta (ID): Kementerian Pemberdayaan Perempuan dan Perlindungan Anak.[Internet].[Diunduh pada 11 Mei 2018].

[4]. Ziebolz D, Werner C, Schmalz G, Nitschke I, Haak R, Mausberg RF, Chenot JF. Oral Health and nutritional status in nursing home residentsresults of an explorative cross-sectional pilot study. BMC Geriatr. 2017 Jan 31;17(1):39. Pubmed PMID: 28143415.

[5]. Gaszynska E, Szatko F, Godala M, Gaszynski T. Oral health status, dental treatment needs, and barriers to dental care of elderly care home residents in Lodz, Poland. Clin Interv Aging. 2014 Sep 25;9:1637-44. Pubmed PMID: 25284997

[6]. Sinor MZ. Oral health assessment among elderly staying in shelter (Rumah Seri Kenangan), Kelantan, Malaysia. Age. 2013;71:8-38.

[7]. Mohd FN, Said AH, Yusof MZ, Ismail NI, Musa NM. Oral health status and self-perceived oral health satisfaction among residents in the largest care home in east coast Malaysia and its associated factors: A cross-sectional study. Journal of International Oral Health. 2020 Mar 1;12(2):168.

[8]. British Dental Association. Dentistry in Care Homes Research-UK. 2012. BDA UK: UK. p.15.

[9]. Monaghan N, Karki A, Playle R, Johnson I, Morgan M. Measuring oral health impact among care home residents in Wales. Community Dent Health. 2017 Mar;34(1):14-18. Pubmed PMID: 28561552.
[10]. Enny E, Abdul M, Ruhaya H, Zulkarnain S. Oral Hygiene Care and Nutritional Status among Institutionalised Elderly in Kedah and Kelantan, Malaysia. Malaysian Journal of Nutrition. 2015 Oct 1;21(2).

[11]. Husain J, Mohd FN, Said AH, Yaacob M. Oral Health Related Quality of Life Among Adults Attending Periodontal Clinic at IIUM Kuantan. Journal of International Dental and Medical Research. 2020;13(1):252-7.

[12]. Singh SK, Maykanathan D, Xing JT. Oral Health Related Quality of Life (OHRQoL) and its association with sociodemographics and weight status among adults in Klang Valley, Malaysia. Journal of Oral Health \& Research. 2015 Oct $1 ; 6(4)$.

[13]. Saub R, D Locker.The impact of oral conditions on the quality of life of the Malaysian adult population: preliminary results. Med J Malaysia. 2006; 61(4):438-46.

[14]. Saub R, Locker D, Allison P. Derivation and validation of the short version of the Malaysian Oral Health Impact Profile. Community Dent Oral Epidemiol. 2005 Oct;33(5):378-83. Pubmed PMID: 16128798.

[15]. Mohamed N, Saddki N, Yusoff A, Mat Jelani A. Association among oral symptoms, oral health-related quality of life, and health-related quality of life in a sample of adults living with HIV/AIDS in Malaysia. BMC Oral Health. 2017 Aug 22;17(1):119. Pubmed PMID: 28830386.

[16]. Monaghan N, Karki A, Playle R, Johnson I, Morgan M. Measuring oral health impact among care home residents in Wales. Community Dent Health. 2017 Mar;34(1):14-18. Pubmed PMID: 28561552.

[17]. Klotz AL, Hassel AJ, Schröder J, Rammelsberg P, Zenthöfer A. Oral healthrelated quality of life and prosthetic status of nursing home residents with or without dementia. Clin Interv Aging. 2017 Apr 11;12:659-665. Pubmed PMID: 28442895.

[18]. White DA, Tsakos G, Pitts NB, Fuller E, Douglas GV, Murray JJ, et al. Adult Dental Health Survey 2009: common oral health conditions and their impact on the population. Br Dent J. 2012 Dec;213(11):567-72. Pubmed PMID: 23222333.

[19]. Virdi M, editor. Emerging Trends in Oral Health Sciences and Dentistry. BoD-Books on Demand; 2015 Mar 11.

[20]. Cornejo M, Pérez G, de Lima KC, Casals-Peidro E, Borrell C. Oral HealthRelated Quality of Life in institutionalized elderly in Barcelona (Spain). Med Oral Patol Oral Cir Bucal. 2013 Mar 1;18(2):e285-92. Pubmed PMID: 23385501.

[21]. Nicol R, Petrina Sweeney M, McHugh S, Bagg J. Effectiveness of health care worker training on the oral health of elderly residents of nursing homes. Community Dent Oral Epidemiol. 2005 Apr;33(2):115-24. Pubmed PMID: 15725174.

[22]. Schimmel M, Leemann B, Christou P, Kiliaridis S, Schnider A, Herrmann FR, et al. Oral health-related quality of life in hospitalised stroke patients. Gerodontology. 2011 Mar;28(1):3-11. Pubmed PMID: 20337725.

[23]. Jang EJ, Kim EK, Lee KS, Lee HK, Choi YH, Hwang TY, et al. Oral health related quality of life and it's related factors of stroke patients at home in Korea. Arch Gerontol Geriatr. 2015 Nov-Dec;61(3):523-8. Pubmed PMID: 26228715.

[24]. Wong FMF, Ng YTY, Leung WK. Oral Health and Its Associated Factors Among Older Institutionalized Residents-A Systematic Review. Int J Environ Res Public Health. 2019 Oct 26;16(21):4132. Pubmed PMID: 31717812 . 